\title{
ON RELATIVE CLAUSES AND LOCATIVE EXPRESSIONS IN ENGLISH EXISTENTIAL SENTENCES
}

\author{
Leiv Egil Breivik
}

\begin{abstract}
In an influential paper, Fox \& Thompson (1990) argue that the grammar of relative clauses in spoken American English is affected by interactive and cognitive factors pertaining to the communication situation. Existential sentences containing a relative clause as well as an overt locative expression figure prominently in their analysis. The present paper examines Fox \& Thompson's analysis of such sentences in the light of a wide range of data. It is shown that the generalizations they make on the basis of their limited corpus (25 tokens) rest on false premises. Their analysis fails to take account of some of the most salient properties inherent in existential sentences in all varieties of English; it also disregards relevant cross-linguistic data. An alternative analysis is offered. ${ }^{1}$
\end{abstract}

Keywords: Existential sentences, Existential there, Relative clauses, Grounding, Information flow, Locative space, Discursive space, English

\section{Introduction}

The present paper is intended as a contribution to the study of the ways that speakers and writers, hearers and readers use language. ${ }^{2}$ It compares data derived from two computerized corpora of British English with the findings presented in Fox \& Thompson's (1990)

${ }^{1}$ I am grateful to Christiane Dalton-Puffer, Bryan Jenner, Karol Janicki, Gunther Kaltenböck, Nikolaus Ritt, Barbara Seidlhofer, Anna-Brita Stenström, Toril Swan and Henry G. Widdowson for useful discussion of issues raised in the paper. This is of course not to say that any of them would necessarily agree with what I say here.

${ }^{2}$ Much recent work in linguistics has been concerned with the relation of utterances and sentences to contexts and situations. For example, this relation has been examined by Abbott (199; Baker (1995); Chafe (1987, 1994); Dillon et al. (1985); Downing \& Noonan (1995); Firbas (1992); Fox \& Thompson (1990); Geis (1995); Givón (1984, 1990, 1994); Gundel (1998); Gundel et al. (1993); Hopper \& Thompson (1980); Huck \& Na (1990); Kiss (1998); and Prince (1988, 1992). Although scholars working in this field may differ in their approaches, their modes of explanation, and their characterization of data, they share the view that regularities and generalizations about language are to be found not only in the rules of its grammar, but also in the way these rules interact with pragmatic factors such as information status and contrastiveness. 
influential paper on relative clauses. On the basis of a quantitative analysis of a corpus of (finite) relative clauses in American English conversations, Fox \& Thompson argue that the grammar of the clauses in question is affected by interactive and cognitive factors inherent in the communication situation. Altogether their corpus consists of 414 relative clauses, representing a wide range of categories (see $\$ 2$ below). There has been no dearth of research into relative clauses in spoken and written English (see Johansson 1995 and references given there). However, Fox \& Thompson's study is the first to examine the relevance of information-flow principles to relative clauses in their conversational contexts. In recent literature, the empirical data and analysis provided by Fox \& Thompson have often been taken as conclusive evidence that discourse-level explanations can account for grammatical facts.

In what follows, I shall restrict my attention to EXISTENTIAL-HEAD RELATIVES, i.e. relative clauses with existential heads, as exemplified by $1-2:^{3}$

There are many people here [who like Christmas pudding].

There was a girl [I had met before].

This is the category which is given the most detailed treatment in Fox \& Thompson's study. Locative expressions play an important role in their analysis of the constructions in question (cf. here in ex. 1). Such expressions will therefore also be dealt with in the present paper. Fox \& Thompson's corpus of existential-head relatives is very small, consisting of only 25 tokens. My primary goal is to find out to what extent their claims about existentialhead relatives and locatives hold when confronted with a larger database. ${ }^{4}$ All the existential-head relatives in the Lancaster-Oslo/Bergen (LOB) Corpus of British English ${ }^{5}$ will be subjected to a systematic examination. Data will also be cited from the Survey of English Usage at University College London. ${ }^{6}$ Finally, reference will be made to relevant cross-linguistic data, an aspect which is not mentioned at all by Fox \& Thompson despite the vast amount of research carried out in this field.

In discussing relative clauses and their contexts of use, it will be convenient to adopt some of the most important concepts and terms in Fox \& Thompson's analysis. For the

\footnotetext{
${ }^{3}$ Throughout this paper, the relative clause will be given in square brackets and the head NP in italics.

${ }^{4}$ For a full discussion of existential constructions, see Bolinger 1977; Breivik 1981, 1990, 1997a; Ebeling 1999; Erdmann 1976; Hannay 1985; Lumsden 1988; McNally 1997; and Milsark 1974.

${ }^{5}$ The LOB Corpus is a one-million word collection of present-day British English written texts (published in 1961). Like its American counterpart, the Brown Corpus, it contains 500 text samples of approximately 2,000 words distributed over 15 text categories. The LOB Corpus is now available on CDROM and is distributed by the Centre for Humanistic Information Technology at the University of Bergen

${ }^{6}$ The one-million word Survey Corpus samples spoken and written British English produced between c. 1955 and 1985 . It comprises 100 spoken and 100 written texts, each of approximately 5,000 words. The texts range from learned and technical writing to the most spontaneous colloquial English, including telephone conversations. The Survey Corpus was originally compiled on paper, in the form of many thousands of slips, with detailed grammatical annotations. It has now been computerized and is available on the network of computers at the Survey premises at University College London.
} 
sake of clarity, therefore, I shall first introduce, define and exemplify these concepts and terms, as well as present some of Fox \& Thompson's data and hypotheses that are relevant to my own investigation ( $\$ 2) . \S 3.1$ outlines the syntactic and distributional characteristics of the various types of existential-head relatives occurring in the LOB Corpus. In §3.2, I propose explanations for my findings in terms of semantic, syntactic, and pragmatic factors. Here I relate my findings to Fox \& Thompson's analysis and show that when the database is extended, their analysis fails to account for some of the most salient features of existential sentences. The main results of my investigation are summed up in $\S 4$.

\section{Fox \& Thompson's analysis}

Fox \& Thompson categorize relative clauses according to the role of the head NP within the main clause and of the coreferent $\left(\mathrm{NP}_{\text {rel }}\right)$ within the relative clause. Note that the $\mathrm{NP}_{\text {rel }}$ may not be explicitly expressed, as in ex. 2 above. In addition to existential heads (Ex), the head-NP roles occurring in Fox \& Thompson's corpus are: Subject (S), Object $(\mathrm{O})$, prepositional phrase object (PPO), and predicate nominal (PN). S, O, and PPO also occur in $\mathrm{NP}_{\text {rel }}$ roles. The term X-RELATIVE refers to the role of the $\mathrm{NP}_{\text {rel }}$; thus OBJECT-RELATIVE, for example, stands for a relative clause in which the NP ${ }_{\text {rel }}$ is the object. The examples below, taken from Fox \& Thompson (298-299), illustrate some of the combinations of head $\mathrm{NP}$ and $\mathrm{NP}_{\text {rel }}$ occurring in their corpus:

(3) S-S: the blond kid [that's been setting the fires] is on the 3rd floor

S-O: This man [who I have for linguistics] is really too much

O-S: I know somebody [who has her now]

$\mathrm{O}-\mathrm{O}:$ if you give them the dimensions [you want]

O-PPO: you know the place [where she lives]

PN-S: it's the only place [that carries the book]

Ex-S: there's something really sad [that happens]

Ex-O: there was something [we needed]

Ex-PPO there's three courses already [that I'm not going to do well in]

Like Fox \& Thompson, I shall distinguish between two types of subjects in the relative clause: ' $A$ ' $\left(\mathrm{NP}_{\text {rel }}\right.$ is the subject of a transitive verb) and ' $\mathrm{S}$ ' $\left(\mathrm{NP}_{\text {rel }}\right.$ is the subject of an intransitive verb). The term 'subject' will henceforth refer to the grammatical role 'subject' (including ' $A$ ' and ' $S$ '), while ' $S$ ' will refer only to the subject of an intransitive verb and 'A' only to the subject of a transitive verb.

Fox \& Thompson posit five information-flow factors that are claimed to play an important role in explaining the grammatical patterns of relative clauses: "These factors are both cognitive and interactional, being constituted in terms of both the speaker's model of the hearer and the interaction between the speaker and the hearer" (299). ${ }^{7}$ Only the first

${ }^{7}$ Here Fox \& Thompson's analysis is strongly influenced by Chafe's important 1987 paper entitled "Cognitive constraints on information flow". Chafe interprets a piece of discourse in terms of cognitive factors that interact to determine its content and shape. He assumes "that the linguistic phenomena which have been given names like ['given and new information' and 'topics and comments'] are manifestations of basic 
three factors mentioned by Fox \& Thompson have bearing on the issues discussed in $\S 3.2$ below. We shall therefore content ourselves with a brief look at these.

The first factor is the information status of the NP containing the relative clause. To explore this dimension of the problem, Fox \& Thompson use the following categories: NEW (the referent is presumed not to be in the addressee's focal consciousness), GIVEN (the referent is presumed to be in the addressee's focal consciousness), and IDENTIFIABLE (the addressee is able to identify the referent, e.g. by prior knowledge).

The second factor that is claimed to play a prominent role in explaining relative clause patterns has to do with the way the referent of an NP is located in conversational space, how it is made relevant to the addressee at the point where it is introduced. This is called GROUNDING. Or, to be more specific, to ground an NP is to relate it to a given referent in the immediate context, i.e. to a referent that is presumed to be in the addressee's focal consciousness. ANCHORING, MAIN-CLAUSE GROUNDING, and PROPOSITION-LINKING are special types of grounding. These types can be illustrated by the following examples from Fox \& Thompson's material:

\section{Anchoring}

(4) (talking about upkeep on houses)

But uh - the original price of it, eh - you can't even (inaud.) the original price, just that little screen porch alone is five hundred dollars, the air condish - the uh heater thing [we put in] I think was a hundred uh five six hundred dollars,

\section{Main-clause grounding}

(5) he's got - a spring [that comes way up],

\section{Proposition-linking}

(6) The mother's sister is a real bigot. Y'know and she hates anyone [who isn't a Catholic].

Following Prince (1981), Fox \& Thompson define anchoring as the linking of a new referent in an NP to another referent in the same NP. In ex. 4 the subject of the relative clause, we, is given since the speaker is a participant in the conversation, and the relative clause anchors the uh heater thing by linking it to the given referent. In the case of mainclause grounding, "the Head NP is grounded by virtue of being associated with a Given referent in the same main clause, as opposed to being grounded by virtue of its relative clause" (Fox \& Thompson 1990: 301). 5 provides an example of this; the main-clause subject he (given referent) grounds the object a spring. Finally, Fox $\&$ Thompson give 6 as an example of proposition-linking. Here the NP anyone who isn't a Catholic is grounded by its link to the preceding proposition where the mother's sister is characterized as a bigot.

The third information-flow factor that supposedly affects the grammar of relative clauses in Fox \& Thompson's data is humanness. It is argued that the humanness of both the referent of the $\mathrm{NP}_{\text {rel }}$ and of the other NPs in the relative clause is relevant in explaining

cognitive processes, and that we can never understand them fully until we understand the psychological phenomena underlying them" (1987: 21). 
the distribution of the various types of relative clause.

As far as there-sentences are concerned, Fox \& Thompson are mainly concerned with human existential heads. They claim that relative clauses generally do not serve an anchoring function in such constructions: "in Existential-Head utterances grounding is often accomplished with main-clause grounding by means of a locative expression or by proposition-linking, rather than with anchoring, as in an Object-relative" (309). Thus the utterances in question are claimed to be very different from those constructions which have an ordinary (nonhuman) subject. In the latter case the grounding is typically provided by the relative clause. The authors give the existential-head utterances in 7 and 8 as examples of main-clause grounding and proposition-linking respectively.

(7) There were two people there [who were constantly on stage]

(8) B: Y'know I've been reading about very old people lately, $(0.4)$

A: $\quad$ Yea//:h?

B: Like they had an article in the Rolling Stone with this guy who's supposed to be a hundred and thirty. The oldest American. He's a black guy who lives in Florida and they interviewed him, ...

B: and one thing they said in the article that was really intriguing was, in the United States at this point, there are over a hundred thousand people [who are over a hundred years old]

In 7 the existential head is made relevant by the locative expression there, while in 8 the relative clause who are over a hundred years old provides the grounding for the existential head, the relative clause being linked to the earlier proposition I've been reading about very old people lately.

\section{Existential-head relatives in LOB}

\subsection{Presentation of data}

The LOB Corpus contains 399 finite relative clauses with an existential head. Following Fox \& Thompson, no distinction has been made between restrictive and nonrestrictive clauses. Table 1 summarizes the distribution of grammatical roles for the $\mathrm{NP}_{\text {rel }}$ in the LOB material. To facilitate comparison with Fox \& Thompson's analysis, the relevant figures from their corpus are also given in Table 1. As far as the LOB material is concerned, the $\mathrm{NP}_{\text {rel }}$ role in the 'other' category is PPO in the vast majority of cases.

Table 2 gives the frequency of the various types of $\mathrm{NP}_{\text {rel }}$ subsumed under 'other' in Table 1. The whole prepositional phrase in which $\mathrm{NP}_{\text {rel }}$ occurs usually functions as an adverbial. Table 2 distinguishes five categories according to the semantic role of the prepositional phrase: Space, time, cause, manner, and instrument. In adverbial expressions of space, time, and cause, the prepositional phrase can be replaced by the special adverbs where, when, and why respectively. Cases where the relative pronoun is the possessive determiner whose are also included in the 'other' category in Table 1, irrespective of the syntactic function of the NP in which whose occurs. Finally, items which are not captured 
by the above categories or which do not readily lend themselves to a semantic classification are assigned to the 'miscellaneous' category in Table 2.

The categories displayed in Tables 1 and 2 are illustrated by specimens from the corpus in exx. 9-32. ${ }^{8}$ The textual examples in 33-39 contain various other clauses which will be briefly discussed in connection with some of the points made in $§ 3.2$. In 33 and 34 the head of the main-clause subject (the existential head) is postmodified by a nonfinite infinitive clause. Such clauses are allied to finite relative clauses and are therefore often referred to as relative infinitives (for a full discussion, see Geisler 1995). 35-37 have postmodification by what Quirk et al. (1985: 1263-1265) call -ing and -ed participle clauses, while 38 and 39 illustrate appositive postmodification by finite and nonfinite clauses. $^{9}$

Table 1. Distribution of grammatical roles for all $\mathrm{NP}_{\text {rel }}$ in existential-head relatives in LOB and in Fox \& Thompson's (FT) corpus.

\begin{tabular}{|c|c|c|c|c|c|}
\hline \multirow[b]{2}{*}{$\mathrm{NP}_{\text {rel }}$} & \multicolumn{2}{|c|}{ Subject } & \multirow[b]{2}{*}{$\mathrm{O}$} & \multirow[b]{2}{*}{ Other } & \multirow[b]{2}{*}{ Total } \\
\hline & A & $\mathrm{S}$ & & & \\
\hline LOB & $143(36 \%)$ & $65(16 \%)$ & $71(18 \%)$ & $120(30 \%)$ & $399(100 \%)$ \\
\hline FT & $7(28 \%)$ & $13(52 \%)$ & $4(16 \%)$ & $1(4 \%)$ & $25(100 \%)$ \\
\hline
\end{tabular}

Table 2. Frequency of the various categories subsumed under 'other' in Table 1.

\begin{tabular}{|lr|}
\hline PPO/Space (preposition $+\mathrm{NP}_{\text {rel }}$ ) & 19 \\
PPO/Space (Where (ever)) & 19 \\
PPO/Time (preposition $+\mathrm{NP}_{\text {rel }}$ & 2 \\
PPO/Time (When) & 26 \\
PPO/Cause & 23 \\
PPO/Manner & 1 \\
PPO/Instrument & 3 \\
Whose & 8 \\
Miscellaneous & 19 \\
\hline Total & 120 \\
\hline
\end{tabular}

\footnotetext{
${ }^{8}$ Quotations from the LOB Corpus are provided with the appropriate reference-code (e.g. A: Press: reportage A13: 83).

${ }^{9}$ In the following examples, the participle clauses correspond to finite relative clauses in which the relative pronoun is subject: The person (who is) writing this article is from Norway and An article (that has been) written by a person from Norway will appear in the June issue. Quirk et al. point out that -ing forms in such clauses should not be seen as abbreviated progressive forms in relative clauses, since stative verbs, "which cannot have the progressive in the finite verb phrase, can appear in participial form" (1985: 1263), as in This is a liquid with a taste (*which is) resembling that of soapy water.
} 


\section{A-relatives}

(9) there are many Australian citizens [who will fill the office as well or better than Lord de l'Isle will fill it]. (A:Press:reportage A13: 83)

(10) there may indeed be books [which compel a good reading in the sense that no one who reads in the wrong way would be likely to get through more than a few of their pages]. (G:Belle lettres,biog G38: 63)

(11) there wasn't a man in the world [who would have given her a second glance while Lois was in the room]. (P:Romance,love story P14: 84)

(12) the main body of the company was fully engaged in a training programme but there were at times quite large numbers of men (who had completed their training and were waiting to be drafted overseas]. (G:Belle lettres,biog G23: 84)

\section{$S$-relatives}

(13) there was the severe-looking man [who went about with the heavy plaster round his neck, looking a little sinister as he stiffly turned his body to talk]. (G:Belle lettres,biog G25: 62)

(14) there had been a feeling of hope then [which had gone later]. (K:General fiction K06: 105)

(15) there were desks [which looked as if they had come from massive Victorian offices], and there were dressing-tables [which looked as if they had come from penurious Victorian servants' dormitories]. (L:Mystery,detective L13:69)

\section{Object-relatives}

(16) but there are other important features of the concept of desiring or wanting [which this modern picture simply can not accommodate] and which therefore spell disaster for this view of the matter. (J:Learned,scientific J54: 25)

(17) there was nothing on the floor [that I could see]. (L:Mystery,detective L12: 83)

(18) there was a surprised excitement in his voice [that I should have found extremely flattering had not experience counselled me against a readiness to believe that here, at last, I was about to meet the perfect, that dream reader whom every novelist is convinced must exist somewhere, the one reader who has not only read everything that he has written, but read between the lines]. (P:Romance,love story P19: 66)

PPO/Space

(19) there is another point [at which he swerves from the strict Stoic creed]. (D:Religion D09: 72)

(20) there are a dozen countries [where a man could easily hide up and change the money without danger]. (L:Mystery,detective L04: 124)

(21) there are no white horses, though there is a thin white line [wherever wave meets rock along the island shores] and, beyond them, a slow heave along the line of the horizon which shows that, away out there, a fair swell must be running, still. (E:Skills, hobbies E15: 79) 


\section{PPO/Time}

(22) for all that, as far as England is concerned, there have been only two occasions [on which a body has been found in a tunnel in circumstances pointing to murder]. (F:Popular lore F04: 51)

(23) education as a profession, like other professions, has fluctuated and there was a time [when teachers were shockingly underpaid]. (B:Press:editorial B27: 68)

(24) there had been no moment [when I reassessed her character, noticed new qualities, or passed less harsh judgements on the old ones: Which seemed to imply that I now loved her for the same things for which I had previously disliked her heartily; if indeed I had ever disliked her]. (K:General fiction K15: 15)

\section{PPO/Cause}

(25) there is every reason [why he should have a home farm], but otherwise he should live by rents. (G:Belle lettres,biog G35: 33)

(26) there is, admittedly, no overriding reason for picking 100 years as the natural term of life for a house, rather than, say, eighty years; nor is there any special reason [why the backlog should be cleared in twenty years, rather than in ten or thirty (J:Learned,scientific J47: 7)

\section{PO/Manner}

(27) prices of course depend on local availability of materials and, there are many ways [in which costs can be saved]. (E:Skills,hobbies E04: 43)

\section{PPO/Instrument}

(28) there's an old trick [whereby you can, theoretically, disarm a man if he'll stand still for it]. (N:Adventure,western N15: 5)

Whose

(29) until 1940 it was an observable fact that there were composers [whose music was highly prized in some countries and entirely neglected by their neighbours], and this was explained by the difference in national characters. (A:Press:reportage A17:4)

\section{Miscellaneous}

(30) the spinel unit cell (see fig 2.1) consists of a close packed cubic array of 32 oxygen anions, between which there are 96 spaces or interstices, [24 of which are filled with a cation, the remaining 72 being empty]. (J:Learned,scientific J70: 14)

(31) in the first case the fact is there waiting to be discovered as it were, but there is no intention [of which one is ignorant in the second case]. (G:Belle lettres,biog G63:29)

(32) there are places in Africa [of which this can not be said]. G:Belle lettres,biog G73: 35)

\section{Relative infinitives}

(33) all was safe here; there were no ditches [to fall into], but close on either side tall hedges grew with shoots of many flavours. (G:Belle lettres,biog G19: 64) 
(34) there is no time [to examine the victim], no time [to loosen clothing or clear the airway] - these matters must be left until artificial respiration by any recommended method has been commenced. (J:Learned,scientific J16: 60)

\section{Participle clauses}

(35) while there is a story [meandering through the book], the main object of many chapters is to record some improbable and unpleasant anecdote. (C:Press:reviews C01: 59)

(36) there were tins of food all over the floor, and there were women's magazines [scattered around]. A:Press:reportage A12: 33)

(37) where the big gates of the Hall should have hung between their massive pillars, there was simply a gap [giving on to a driveway, green and mossy, its twin tracks no longer worn by wheels, but matted over by the discs of plantain and hawkweed, rings of weed spreading and overlapping like the rings that grow and ripple over each other when a handful of gravel is thrown into water]. (L:Mystery,detective L09: 45)

\section{Appositive clauses}

(38) there seems to be little doubt [that the inculcation of the habits of mind and behaviour of a constitutional sovereign has been successfully achieved in the cases of George 5, George 6, and the present Queen]. (G:Belle lettres,biog G59: 34)

(39) so there seems to be a need [to re-think the official political philosophy in terms of the realities of power and the demands for strong government]. (G:Belle lettres,biog G60:31)

\subsection{Discussion of the corpus data}

Before embarking on a discussion of the examples cited above, it is necessary to say a few words about spatial and temporal reference. This question, which is passed over in silence by Fox \& Thompson, is of considerable importance when it comes to understanding the interaction between the constituents (including relative clauses) of existential sentences and their contexts of use.

The semantics of existential there in present-day English is a controversial issue. Many scholars claim that it is an NP which is completely devoid of semantic content, its only function being to serve as a syntactic slot-filler (dummy subject). Other scholars posit close affinities between existential there and the locative adverb there. In Breivik (1997a), I argue that existential there has not undergone complete desemanticization; both synchronically and diachronically it can be shown to extend from the homonymous locative adverb. However, the location which existential there designates must be regarded as an abstraction and metaphorical extension. Or, to put it in cognitive terms, it designates what Fauconnier (1985) calls a MENTAL SPACE, i.e. a space where conceptual entities are located. Similar proposals are put forward by Bolinger (1977: 90-123) and Lakoff (1987: 462-585). Whether we take this view of the matter or not, the locative basis of existential sentences is hardly open to doubt and has been widely recognized. Bolinger states: (existence). Location and existence are the two extremes, but there is no dividing line between them. 
Whether we say Is there a God? or Is there a God in the universe? we are expressing the same locative. To exist, a thing has to be somewhere (1977: 99).

This takes us to my next point.

The spatialization of time is a pervasive phenomenon in the grammatical and lexical structure of the world's languages. We shall not go into the various controversies associated with localism, which "is the belief that semantic and conceptual information is reducible to concrete spatial information (whence the name localism, or locale). Adherents of localism point to the ontological primacy of the physical world to argue for the spatial base of all reference and predication" (Frawley 1992: 229; see also Anderson 1971: 5-9). There are stronger and weaker versions of the localist hypothesis. The weak version "is restricted to the incontrovertible fact that temporal expressions, in many unrelated languages, are patently derived from locative expressions" (Lyons 1977: 718). For our purposes, Haspelmath's (1997) recent cross-linguistic study of temporal adverbials is of particular interest. Here the author cites data showing that languages frequently express temporal and spatial notions in a similar way: "This phenomenon is so widespread in different languages across the world, and in different parts of the vocabulary, that we have to conclude that space and time are linked to each other in human thinking as well" (1997: 1).

Finally, in a discussion of how language denotes and encodes spatio-temporal concepts, it is also relevant to mention deixis, the way an expression is anchored to some point in context. It is well-known that temporal (as well as personal) deixis follows the spatial parameters (cf. Frawley 1992: 274). ${ }^{10}$ Note that the example Fox \& Thompson cite to illustrate main-clause grounding (ex. 7) contains a prototypical deictic expression, the locative adverb there ('not in the vicinity of the speaker'). Alongside there and here, the temporal adverbs now and then are the most obvious instances of expressions that reflect what Lyons (1968: 275) calls "the spatio-temporal co-ordinates of the typical situation of utterance".

Once the spatialization of time has been postulated, the way lies open for assigning the same (localistic) interpretation to both locative and temporal expressions in existential sentences. In this connection we may note the following statement by Lyons (1968: 390): "From the point of view of their semantic analysis, existential sentences might be described as implicitly locative (or temporal). The assertion that something exists, or existed, requires 'complementation' with a locative (or temporal) expression before it can be interpreted". With these preliminaries in mind, we shall now take a closer look at the LOB data and Fox \& Thompson's analysis.

All the examples cited in $\$ 3.1$ locate entities and events in space and time. As I have shown elsewhere (Breivik 1997b), the LOB Corpus contains 2,730 existential sentences. In nearly half of these sentences $(1,232)$, temporal and locative relations are overtly expressed by adverbials or (less commonly) by finite or nonfinite clauses postmodifying the head of the subject NP (84); in the remaining cases, a locative/temporal specification can be inferred from the context. Since I am not concerned, in this paper, to push the hypothesis of localism to the limits of its coverage or to develop it in any detail, I shall

10 The relations between language and space are discussed from various perspectives in Bloom et al. 1996. The fifteen contributions in this volume bring together theoretical viewpoints from such diverse areas as linguistics, psychology, anthropology, and neuroscience. 
make no attempt to relate it explicitly to the other semantic categories posited in $\S 3.1$. Here it is sufficient to note that adverbials of cause, manner, and instrument may also be analysed in spatial terms. Lyons (1977: 721-722) writes: "Even instrumental adverbials and adverbials of manner, which, like locative, temporal and causal adverbials are characteristically adjuncts, rather than nuclear constituents, in simple sentences, may be brought together, from a localistic point of view, and analysed in terms of the notion of a path (cf. Anderson 1971: 171)". As can be seen from Table 2 and the examples cited in $\S 3.1$, it is precisely the categories mentioned by Lyons that are found in existential sentences.

There can be no doubt that Fox \& Thompson's analysis captures some important generalizations about relative clauses in spoken American English. However, it is equally clear that their account of this type of discourse does not provide a principled explanation of the LOB data. Indeed, as we shall see below, my findings cast serious doubt on some of the rather bold claims they make about the existential sentences in their corpus which, consisting of only 25 tokens (cf. Table 1), can hardly be said to be a reliable basis for an empirical investigation.

First, main-clause grounding in the sense of Fox \& Thompson is not a salient feature of existential sentences in LOB. Admittedly, my material does contain instances where a locative expression in the main clause could be said to provide the grounding necessary to make the head of the subject NP relevant, as in ex. 17, but the prototypical there-sentence in LOB (regardless of whether the existential head is human or nonhuman) cannot be given such an analysis; the vast majority of the corpus sentences resemble examples like 9 and 10 where the locative is not overtly expressed, or examples like 11 where the locative is expressed but does not represent given information in the sense of Fox \& Thompson. The wider context in which ex. 11 occurs shows that the referent of the locative expression in the world is not presumed to be in the addressee's focal consciousness and thus cannot ground the existential head a man. This is of course different from saying that the referent of the locative is not known to the addressee (on the distinction between given and identifiable referents, see $\S 2$ above). We thus see that the vast majority of the LOB sentences have no main-clause grounding of the existential head.

In exx. 19-24, the locative/temporal specification is realized by finite relative clauses, while 33 and 34 make use of nonfinite relative clauses. In 33 and 34 the subject NP (existential head + postmodifying infinitive clause) expresses locative and temporal meaning respectively. In such cases it is often possible to introduce a relative pronoun and retain the infinitive clause, or to use a full relative clause with preposition + relative pronoun or the adverbial relative where/when without preposition (cf. Quirk et al. 1985: 1266). The locative/temporal meaning of constructions like 33 and 34 is made explicit in the following examples: The place to stay is the new hotel near the river / The place at which to stay is ... / The place at which you should stay is ... / The place where you should stay is ...; The time to visit Vienna is August / The time at which to visit Vienna is ... / The time at which you should visit Vienna is ... / The time when you should visit Vienna is ...

Exx. 35 and 36 further demonstrate that Fox \& Thompson's analysis is not optimal for existential sentences in my material. In 35 the locative expression occurs in the postmodifying participle clause. In the two coordinated there-clauses in 36 , we find mainclause grounding in the first clause only; the second there-clause has the grounding element in the subordinate clause. Note also that it is not uncommon for existentials to have the 
locative specification in a finite relative clause (cf. There is a famous linguist who lives here). I would claim that the key to understanding the occurrence of locative (and temporal) expressions in the sentences under discussion is provided by semantic rather than by information-flow factors. As we saw above, the localistic interpretation of such sentences is eminently plausible.

As far as proposition-linking is concerned, it does not play an important role in the LOB Corpus. Although it occurs in my material (cf. exx. 12 and 26), the principal function of relative clauses is to identify and describe the referent of the existential head, and not to make it relevant by a link to an earlier proposition. It should be borne in mind that existential sentences are presentative constructions; the most important information is carried by the subject NP. Or, as Huddleston \& Pullum (2002: 1396) put it:

The existential construction is characteristically used to introduce addressee-new entities into the discourse, and for this reason the displaced subject NP is usually indefinite. In many cases, the presence of an indefinite NP makes the existential pragmatically obligatory in that the corresponding non-existential is infelicitous ...

In view of this, it is not surprising that existential-head relative clauses in LOB are often long and complex, containing embedded clauses and modifiers, as in ex. 18. Pragmatically, relative clauses have the same function as other finite and nonfinite postmodifiers. Indeed, as we saw above (note 8) postmodifying -ing and -ed clauses correspond to finite relative clauses in which the relative pronoun is subject. Compare in this connection 18 with 37 which contains a postmodifying participle clause. Both of these examples illustrate how the there-construction makes it possible for subjects to carry very heavy informational loads. In 18 and 37, the location of the head referent is encoded by in his voice and where the big gates of the Hall should have hung between their massive pillars respectively. Note that in both examples the position of the locative adverbial allows (the heaviest part of) the subject to occur in end-position, in accordance with the principles of end-focus and end-weight. (In 18 the subject NP is discontinuous; the long and heavy postmodification is separated from its head by the locative expression.)

In this connection it is worth pointing out that the spoken material of the Survey of English Usage, which includes conversational English, lends no support to the claims Fox $\&$ Thompson make about main-clause grounding and proposition-linking. Altogether the spoken Survey material contains 1,976 instances of existential there. Also in this type of English, the there-construction is used to present new information by locating entities and events in space and time (which, as pointed out above, is different from grounding them in the sense of Fox \& Thompson). Proposition-linking is of marginal importance, and existential-head relative clauses have the same function as other finite and nonfinite modifiers. Needless to say, such modifiers (and the subject NPs in which they occur) are generally less complex than in written English. Indeed, in this material the subject NP frequently occurs without postmodification, and locative/temporal expressions tend to be left out when they represent given information. Examples from the Survey material are given in $40-47$ below. ${ }^{11}$

11 Examples from the Survey material are provided with the appropriate reference-code (e.g. S.2.4b.23). In the present paper, these examples are simplified in that no suprasegmental or paralinguistic 
(40) there are so many people living in London at present [who loathe living in London] (S.2.4b.23)

(41) there's a friend of mine [that wants to do surgery] (S.2.9.82)

(42) but there were plenty of people like Ludendorff [who had absolutely no kind of family or anything behind them] (S.2.3.18)

(43) I ought to ring up the others, didn't I? there was another one [I sent it to] (S.4.2.10)

(44) there's another case of it [that she'd heard of at least] (S.4.8)

(45) well, is there anybody apart from you [that is strong on that]? (S.2.6.9)

(46) I didn't mean by making that distinction to suggest that there could be somebody [who would go on a lot about staging plays] (S.2.6.25)

(47) there must have been many northwest Londoners on Thursday [who like your critic set out manfully for Kensington Gore] (S.1.11a.35)

In view of what has been said above about grounding, it is not surprising that the syntactic patterns exhibited by existential-head relatives in LOB are different from those in Fox \& Thompson's database. There are two (closely related) issues which should be discussed with respect to the difference between the two corpora: First, the use of Srelatives, A-relatives, and object-relatives, and second, the use of human vs. nonhuman nouns in the existential-head slot.

In Fox \& Thompson's material, there is a preponderance of S-relatives over objectrelatives in clauses with an existential head, the figures being $13(52 \%)$ and $4(16 \%)$ respectively (cf. Table 1). In their attempt to account for the high percentage of S-relatives, they restrict their attention to cases (12 instances) where the existential head has a human referent. Such cases are compared with nonexistential utterances where the referent of the subject NP is nonhuman. The latter type tends to prefer object-relatives ( $77 \%$ of the instances). Fox \& Thompson give the following explanation of the skewings in the distribution of S-relatives and object-relatives in their material:

Human referents that need grounding ... do not need to be related to (other) humans to be grounded. Instead, our data show that they tend to be grounded by being related to their own activities, that is, to earlier predicates, as with a locative or by proposition-linking, as illustrated in [7] and [8]. And this produces S-relatives rather than Object-relatives, since no other NP in the clause is needed to accomplish the grounding (1990: 309) .

This explanation does not hold for the LOB data. As shown by Table 1, the distribution of grammatical roles is different in my material, which contains $71(18 \%)$ object-relatives and only $65(16 \%)$ S-relatives. Note also that A-relatives as well as relatives belonging to the 'other' category are more frequent than S-relatives, the percentages being 36 and 30 respectively. Exx. 9, 11, and 12 contain human head NPs as well as A-relatives. Interestingly, the majority of both S-relatives $(44=68 \%)$ and A-relatives $(88=62 \%)$ have a nonhuman head NP. Note also that A-relatives are very common in the spoken Survey material (cf. exx. 40-42). Furthermore, instances where $\mathrm{NP}_{\text {rel }}$ has the role prepositional object (PPO) occur quite frequently. It does not seem to matter whether the head NP is human or nonhuman (cf. exx. 43 and 44).

features are given. For a full discussion of there-constructions in the spoken Survey material, see Breivik 1990: ch.3. 
Another of Fox \& Thompson's claims which is inconsistent with my data concerns existential heads with nonidentifiable human referents. The 10 heads in their corpus "are all specific; that is, one does not find nonspecific humans mentioned in existential constructions" (311). These heads are compared with object heads with nonidentifiable human referents. The 16 instances of the latter type fall into two categories: Relational terms like brother and sister and heads with nonspecific reference like anybody and somebody. Exx. 48-52, which are taken from Fox \& Thompson (311), illustrate the types mentioned above. According to Fox \& Thompson (312), these findings have important theoretical consequences for the discourse roles of English subjects and objects.

(48) but there's a woman in my class [who's a nurse]

(49) there was a boy [that played the trombone] that he kind of knew

(50) and they have $a$ son [who's 24 or 25]

(51) and she hates anyone [who isn't a Catholic]

(52) Someday I'll find someone [that wears a six and a half]

However, in the LOB material, human existential heads with nonspecific reference are by no means rare, as illustrated by exx. 9, 11, 12, and 29. Equally important, such cases occur frequently in British English conversations. The Survey extracts in 40, 42, and 45-47 should be compared with Fox \& Thompson's examples in 48 and 49. Note especially exx. 45 and 46 which have anybody and somebody respectively in the existential-head slot. As we have seen, Fox \& Thompson posit that these items typically occur as object heads. It would appear that Fox \& Thompson again make generalizations on the basis of insufficient data. Anyone who has listened to sizeable stretches of American English conversations will know that sentences like 40, 42, and 45-47 occur in this variety too.

The facts described in the preceding paragraphs, then, argue against Fox \& Thompson's information-flow analysis of existential sentences. We shall now confront more directly their claim that it is a sine qua non for all NPs containing relative clauses to be related to given referents in the discourse. In their discussion of existential-head relatives, Fox \& Thompson explicitly state that "all Head NPs must be grounded" (308). Although this is a characteristic feature of the 25 heads in their material, it certainly does not apply to all existential sentences in English. It is not uncommon for existential sentences to contain new information only (and hence no element that can be related to earlier predicates). This is often the case with existential constructions that are concerned with ontology, i.e. whether an entity exists or not (cf. Lakoff 1987: 565; Milsark 1974: passim). Such constructions occur in both written and spoken English (including conversational English). 53 and 54 illustrate ontological existentials without a relative clause, while 55 and 56 both contain an existential-head relative. If the locative is not expressed in cases like 53-56, it can be inferred: There is no God and There is no God in the universe express the same proposition (cf. the discussion above of the locative basis of existential sentences).

(53) There is no God.

(54) There is a Santa Claus.

(55) There are children [who never stop complaining].

(56) There are men [who hate football]. 
Finally, it should be mentioned that my claims about existential sentences are consistent with the quantitative findings, as well as the functional interpretation of these findings, presented by Biber et al. (1999: 943-956) in their Longman Grammar of Spoken and Written English. Biber et al. base their description of grammatical and discourse patterns on a large collection of spoken and written texts. In all, the Longman Spoken and Written English Corpus (the LSWE Corpus) contains over 40 million words of text representing four main registers: Conversation, fiction, newspaper language, and academic prose. The LSWE Corpus includes British and American English subcorpora for each of these registers. As far as the subcorpus for conversation is concerned, it "is probably the most representative sampling of this register compiled to date" (Biber et al. 1999: 28), containing 3,929,500 words of British English and 2,480,800 words of American English.

Biber et al. subscribe to the widely held view that existential sentences are primarily used to introduce new elements into the discourse. Of particular interest is the following observation (951): "One context where it is appropriate to focus on the existence of something is at the beginning of a story". Note also that existential sentences occur discourse-initially in the LSWE subcorpus for conversation. In such cases the subject NP commonly takes a demonstrative pronoun, as in 57:

(57) There was this really good-looking bloke and he was like - We, we'd given each other eyes over the bar in this pub and Lottie goes, well if you don't hurry up with him I'm gonna go and have him, if you don't hurry up, you know, and just like marched over. I said, Charlotte give me a break (Biber et al. 1999: 951-52)

None of the discourse-initial existentials Biber et al. cite from their subcorpus for conversation contain a finite relative clause. ${ }^{12}$ However, among their examples we find sentences where the existential head is postmodified by a non-finite clause. Biber et al. cite (952) the following example from newspaper language to illustrate that there-sentences are frequently used for an opening line in a conversational narrative:

(58) There was this wonderful little old lady [called the tissue collector]. She was grey haired, quite dumpy with a white coat on and she came to collect sperm if you wanted it stored.

Furthermore, their corpus data demonstrate that "[a]nother way of using existential there as a springboard in developing the text is when it is used to introduce a series of elements" (952), as in the following example from academic writing:

There are three basic rules [to consider in planning a farm enterprise]: ...

In 59 the existential head is postmodified by a relative infinitive.

\footnotetext{
${ }^{12}$ Biber et al. do not make explicit mention of existential-head relatives, apart from stating that such clauses have the same frequency in conversation and academic prose. About $10 \%$ of all the existential sentences in these registers contain a relative clause, as opposed to only $5 \%$ in fiction and newspaper language.
} 
Another interesting fact which emerges from the LSWE Corpus is that "[m]inimal existential clauses, i.e. clauses which lack both adverbial expansions and subjects with postmodification, are most common in conversation, with academic prose at the other extreme" (Biber et al. 1999: 949). As many as $25 \%$ of all the existentials in the subcorpus for conversation belong to this category. In these sentences, then, there is no main-clause grounding in the sense of Fox \& Thompson. This further corroborates my claim that their approach to existential sentences in conversational English is a blind alley.

Finally, the following statement ties in very well with the observations I made on the basis of the spoken Survey material (cf. above): "Minimal existential clauses occur most frequently in conversation, where there is a tendency to present information in smaller chunks and where information is more often left unexpressed, for the addressee to infer" (Biber et al. 1999: 950).

\section{Conclusion}

In the preceding pages, I have been concerned with existential sentences in general and relative clauses and locative/temporal expressions in particular. My starting-point was Fox \& Thompson's (1990) study of relative clauses in American English conversations. I have used a wide range of corpus data (including data from conversational English) to show that Fox \& Thompson's claims are not borne out. Clearly, Fox \& Thompson have fallen into the trap of making generalizations on the basis of insufficient data. For example, their claim, based on a handful of examples, that "one does not find nonspecific humans mentioned in existential sentences" (311) is patently false. In general, the smallness of their corpus of existential sentences is bound to make one sceptical about their observations (some of which are claimed to have far-reaching theoretical implications). 25 tokens can hardly be said to provide a sound basis for reliable analyses of grammatical and information-flow patterns. Fox \& Thompson themselves appear to have no reservations about the size of their corpus of existentials. In their conclusion they state categorically:

We have shown that the information-flow patterns characteristic of English discourse can explain why
nonhuman Subject Heads tend to occur with Object-relatives, whereas nonhuman Object Heads show
no such tendency. We have also shown that Existential-Head relative clauses tend to be S-relatives,
since the grounding for the human Existential Heads is typically either main-clause grounding or
proposition-linking, and the relative clause generally does not serve an anchoring function (1990:314).

While my data are mainly drawn from written British English, Fox \& Thompson's analysis is based entirely on conversational American English. I am of course aware that written and conversational data can be very different both grammatically and pragmatically. However, it is generally agreed that there are certain syntactic, semantic, and pragmatic properties that are inherent in existential sentences in all varieties of English, and it is these properties that have been the focus of the present paper. I submit that the principles embodied in my British English data (as well as in cross-linguistic data) also apply to the existential sentences in Fox \& Thompson's corpus. Here it should be pointed out that my analysis is compatible with the account of existential sentences presented by Biber et al 
(1999). The extensive corpus used by Biber et al. includes conversational data from both American and British English.

In their discussion of existential-head relatives, Fox $\&$ Thompson make no reference to the widely recognized similarity between locative and temporal notions, but restrict their attention to locatives. In sentences like There is a person here who is seriously ill, the referring expression here is claimed to be an important information-flow factor (mainclause grounding). I have argued that the use of locative and temporal expressions in such cases should be explained on purely semantic grounds. There-sentences express propositions concerning existence; that is, they locate new entities and events in space and time. This is the raison d'd être for the locative/temporal expressions in such sentences. Hence it is not surprising that all there-sentences in the LOB Corpus (as well as in the spoken Survey material) contain a locative/temporal specification which is either overt or can easily be inferred from the context. The locative-semantic argument advanced in the present paper is consonant with much previous research on English existential sentences (see e.g. Bolinger 1977: 90-123; Kuno 1971; Lyons 1967, 1968: 389-390, 1975, 1977: $722-$ 723).

It should be emphasized that in the present paper 'locate in space and time' is not used synonymously with 'ground in space and time', and that my data are incompatible with Fox \& Thompson's analysis. In the prototypical existential sentence, the locative expression does not serve to ground entities in the sense of Fox \& Thompson: According to them, to ground an NP is to relate it to a given referent in the immediate context. In the vast majority of my corpus sentences, the locative (or temporal) expression is either provided by the context or it represents new information; hence Fox \& Thompson's principle of information flow is not even secondary to the ontological conditions on knowledge. In view of my data as well as data presented by other researchers, I find the whole notion of main-clause grounding in existential sentences less than convincing.

My claim that the sentences under discussion are used to locate new entities and events in space and time can also be linked to the broader research context. It is a commonplace that the syntactic properties of existential sentences make them suitable for presenting new information into the discourse in accordance with universal pragmatic principles; they introduce a new referent into locative or discursive space (see e.g. Bolinger 1977: 90-123; Huddleston \& Pullum 2002: 1390-1401; Lakoff 1987: 462-587). The use of existential-head relative clauses should also be seen in this perspective: It is the subject NP that carries the most important information in a there-sentence, and like other NP modifiers relative clauses are used to identify and describe the referent of the existential head. Fox $\&$ Thompson's proposition-linking plays a negligible role in my material. Needless to say, an explanation along the lines proposed above is consistent with the hypothesis advanced in $\$ 3.2$ that existential there itself designates a mental space where conceptual entities are located.

The above account of the use of existential-head relatives and locative/temporal expressions is corroborated by cross-linguistic and typological data; in many languages, sentences which express existence in space and time are the only means of introducing indefinite non-generic NPs into the discourse (cf. Givón 1976: 173).

In his insightful discussion of there-sentences, Lakoff (1987: 581) speaks of "the enormous complexity of the data". Fox \& Thompson's account shows very little awareness of the range of syntactic, semantic, and pragmatic phenomena involved. Indeed, the 
available evidence demonstrates that their approach to existential sentences in conversational English is a blind alley. In other words, although there is no doubt that discourse-level explanations can account for grammatical facts, it is equally clear that Fox $\&$ Thompson's data and analysis cannot be construed as evidence for this.

\section{References}

Abbott, Barbara (1997) Definiteness and existentials. Language 73: 103-108.

Anderson, John (1971) The grammar of case: Towards a localistic theory. Cambridge: Cambridge University Press.

Baker, C.L. (1995) Contrast, discourse prominence, and intensification, with special reference to locally free reflexives in British English. Language 71: 63-101.

Biber, Douglas, Stig Johansson, Geoffrey Leech, Susan Conrad, \& Edward Finegan (1999) Longman grammar of spoken and written English. London: Longman.

Bloom, Paul, Mary A. Peterson, Lynn Nadel, \& Merrill F. Garrett (eds.) (1996) Language and space. Cambridge, MA \& London: MIT Press.

Bolinger, Dwight (1977) Meaning and form. London \& New York: Longman.

Breivik, Leiv Egil (1981) On the interpretation of existential there. Language 57: 1-25.

Breivik, Leiv Egil (1990) Existential there: A synchronic and diachronic study. Oslo: Novus.

Breivik, Leiv Egil (1997a) There in space and time. In Heinrich Ramisch and Kenneth Wynne (eds.), Language in time and space: Studies in honour of Wolfgang Viereck on the occasion of his 60th birthday. Stuttgart: Franz Steiner Verlag, pp. 32-45.

Breivik, Leiv Egil (1997b) On the interrelation of syntax, semantics, and pragmatics: A study of locative/temporal expressions in existential sentences in the LOB Corpus. In Udo

Fries, Viviane Müller, \& Peter Schneider (eds.), From Alfric to the New York Times: Studies in English corpus linguistics. (Language and Computers: Studies in Practical Linguistics, 19.) Amsterdam \& Atlanta, GA: Rodopi, pp. 1-10.

Breivik, Leiv Egi1 (1999) On the pragmatic function of relative clauses and locative expressions in existential sentences in the LOB Corpus. In Hilde Hasselg ård \& Signe Oksefjell (eds.), Out of corpora: Studies in honour of Stig Johansson. (Language and Computers: Studies in Practical Linguistics, 26.) Amsterdam \& Atlanta, GA: Rodopi, pp. 121-135.

Brown, Gillian, and George Yule (1983) Discourse analysis. Cambridge: Cambridge University Press.

Chafe, Wallace (1987) Cognitive constraints on information flow. In Russel S. Tomlin (ed.), Coherence and grounding in discourse. Amsterdam: John Benjamins, pp. 21-51.

Chafe, Wallace (1994) Discourse, consciousness, and time: The flow and displacement of conscious experience in speaking and writing. Chicago: University of Chicago Press.

Dillon, George L., Linda Coleman, Jeanne Fahnestock, \& Michael Agar (1985) Review article on Brown \& Yule (1983), Leech(1983), and Levinson (1983). Language 61: 446-460. 
Downing, Pamela, \& Michael Noonan (1995) Word order in discourse. Amsterdam and Philadelphia: John Benjamins.

Ebeling, Jarle (1999) Presentative constructions in English and Norwegian: A corpus-based contrastive study. Doctoral dissertation. (Acta Humaniora, 68.) Oslo: Department of British and American Studies, University of Oslo.

Erdmann, Peter (1976) There sentences in English: A relational study based on a corpus of written texts. (Sprach- und Literaturwissenschaften, 6.) Munich: Tuduv.

Fauconnier, Gilles (1985) Mental spaces. Cambridge, MA: MIT Press.

Firbas, Jan (1992) Functional sentence perspective in written and spoken communication . Cambridge: Cambridge University Press.

Fox, Barbara A., \& Sandra A. Thompson (1990) A discourse explanation of the grammar of relative clauses in English conversation. Language 66: 297-316.

Frawley, William (1992) Linguistic semantics. Hillsdale, NJ: Lawrence Erlbaum Associates.

Geis, Michael L. (1995) Speech acts and conversational interaction. Cambridge: Cambridge University Press.

Geisler, Christer (1995) Relative infinitives in English. (Studia Anglistica Upsaliensia, 91.) Stockholm: Almqvist \& Wiksell.

Givón, Talmy (1976) Topic, pronoun and grammatical agreement. In Charles N. Li (ed.), Subject and topic. New York \& London: Academic Press, pp. 149-188.

Givón, Talmy (1984) Syntax: A functional-typological introduction, vol. 1. Amsterdam \& Philadelphia: John Benjamins.

Givón, Talmy (1990) Syntax: A functional-typological introduction, vol. 2 . Amsterdam and Philadelphia: John Benjamins.

Givón, Talmy (ed.) (1994) Voice and inversion. Amsterdam: John Benjamins.

Gundel, Jeanette K. (1998) Review of Downing \& Noonan 1995. Language 74: 185-189.

Gundel, Jeanette K., Nancy Hedberg, \& Ron Zacharski (1993) Cognitive status and the form of referring expressions in discourse. Language 69: 274-307.

Hannay, Michael (1985) English existentials in functional grammar . (Functional Grammar Series, 3.) Dordrecht: Foris.

Haspelmath, Martin (1997) Temporal adverbials in the world's languages. (LINCOM Studies in Theoretical Linguistics, 3.) Munich \& Newcastle: LINCOM EUROPA.

Hopper, Paul J., \& Sandra A. Thompson (1980) Transitivity in grammar and discourseLanguage 56: 251299.

Huck, Geoffrey J., \& Younghee Na (1990) Extraposition and focus. Language 66: 51-77.

Huddleston, Rodney, \& Geoffrey K. Pullum (2002) The Cambridge grammar of the English language. Cambridge: Cambridge University Press.

Johansson, Christine (1995) The relativizers whose and of which in present-day English. (Studia Anglistica Upsaliensia, 90.) Stockholm: Almqvist \& Wiksell. 
Kiss, Katalin É. (1998) Identificational focus versus information focus. Language 74: 245-273.

Kuno, Susumu (1971) The position of locatives in existential sentences. Linguistic Inquiry 2: 333-378.

Lakoff, George (1987) Women, fire, and dangerous things: What categories reveal about the mind. Chicago \& London: The University of Chicago Press.

Leech, Geoffrey N. (1983) Principles of pragmatics. London \& New York: Longman.

Levinson, Stephen C. (1983) Pragmatics. Cambridge: Cambridge University Press.

Lumsden, Michael (1988)Existential sentences: Their structure and meaning. London, New York, \& Sydney: Croom Helm.

Lyons, John (1967) A note on possessive, existential and locative sentences. Foundations of Language 3: 390-396.

Lyons, John (1968) Introduction to theoretical linguistics. Cambridge: Cambridge University Press.

Lyons, John (1975) Deixis as the source of reference. In Edward L. Keenan (ed.), Formal semantics of natural language. London \& New York: Cambridge University Press, pp. 61-83.

Lyons, John (1977). Semantics, vols. 1-2. Cambridge: Cambridge University Press.

McNally, Louise (1997) A semantics for the English existential construction. New York \& London: Garland.

Milsark, Gary Lee (1974) Existential sentences in English. MIT dissertation. [Published in the series Outstanding Dissertations in Linguistics, New York \& London: Garland, 1979.]

Prince, Ellen (1981) Toward a typology of given-new information. In Peter Cole (ed.), Radical pragmatics. New York: Academic Press, pp. 223-255.

Prince, Ellen (1988) The discourse functions of Yiddish expletive + subject-postposing. IPrA Papers in Pragmatics 2: 176-194.

Prince, Ellen (1992) The ZPG letter: Subjects, definiteness, and information status. In William C. Mann \& Sandra A. Thompson (eds.), Discourse description: Diverse analyses of a fundraising text. Amsterdam: John Benjamins, pp. 295-325.

Quirk, Randolph, Sidney Greenbaum, Geoffrey Leech, \& Jan Svartvik (1985) A comprehensive grammar of the English language. London \& New York: Longman. 